described. They are not due to any heart lesion, for people with heart disease do not have such pulsating phenomena except during attacks of palpitation.

The other cases which I have seen have not all been so severe and obstinate as the above four, but the patients have shown the low tension pulse, vasomotor weakness of extremities, subjective sense of beating felt most in the head, epigastric pulse, dermographic skin, insomnia, nervousness and mental depression.

Etiology--So far as my experience goes, the cases occur in young men or adults under 40 . I have not seen this form of disorder in women except in the modified type described. The abuse of tobacco and alcohol, particularly the former, was the conspicuous exciting cause in two cases, while tobacco and alcohol and sexual excesses were factors in the others.

Pathology.-The instability of the vasomotor system in neurasthenics is well known and has been particularly shown by Wolf (Allg. Zeitsch $f$. Psych. xxiv.) and Anjel (Arch.f. Psych. viii., 2). The special symptoms of palpitation, of epigastric pulse and of tinnitus, fullness of the head, head pressure and throbbing are also familiar. But the patients I describe have more than this. There is a general pulsation of the body felt most annoyingly in the head but also in the trunk. One patient (Case 2), when suspended in a Sayre's apparatus, could be distinctly seen to move with each beat of the heart.

It appears to me that in this condition there is an abnormal relaxation of the arterioles and capillaries, the blood is thrown into tubes that have lost their resiliency and thus the pulse waves are not fused together. It is as though a liquid were thrown through a series of tubes with flabby non-elastic walls. Hence the heart-beat is strongly felt all along their course as far as the capillaries. Besides this there is after a $\operatorname{tim} \theta$ a hypochondriacal element in their cases. The patient's attention becomes fixed unalterably on his sensations.

Van Hósslein (Miller's Handbuch der Neurasthenic, p. 127) describes the case of a neurasthenic who suffered from epigastric pulsation. This tormented him so that he went to a surgeon who opened the abdomen thinking he had an aneurysm. The abdominal aorta was found to be perfectly normal; the wound healed and the patient was cured.

I doubt if Dr. Powell's success can be accounted for in this way, because he only cured one side of the man. Yet it seemed to help him generally and permanently more than one would expect from the nature of the operation.

Symptoms and Diagnosis.-I have already referred to the characteristic symptoms of the malady. The patient is neurasthenic and presents the general symptoms of this condition. But his special symptom is the sense of beating of which he never loses the consciousness. He has a low tension pulse of normal or but slightly accelerated rhythm; he does not have palpitations occurring in paroxysms as in Basedow's disease. He may or may not have tremor; there is a striking degree of dermography, and an epigastric pulsation. Pressure on the carotid stops the beating on the corresponding side of the head. There is no evidence of exophthalmic goitre. There is, usually, insomnia, nervousness and mental depression.

Treatment.-The striking success of surgical treatment in one case leads me to believe that ligature of an artery is the surest cure for the disorder. Still in the milder and less typical forms, cure is obtained by the use of general and vasomotor tonics, in other words by the ordinary treatment for neurasthenia. I have found no benefit from ergot. Restrictions must be promptly placed upon the use of tobacco, alcohol and sexual indulgence. Potassium iodid, hyocine, hydriodic acid and arsenic sometimes act well in this as in other forms of vasomotor neuroses. Aconitia in doses of. gr. 1-200 may be of service. I strongly advise against the use of the bicycle in these cases.

A prescription containing bromid of iron gr. $\frac{1}{4}$, bromid of potassium grs. $x$, hydrobromic acid $m$ viii and spartein sulphate gr. $\frac{1}{3}$, gives relief in many cases. Bromid of camphor and strychnia are often useful. I insist, when possible, upon the patient taking hy. drotherapy in the form of a Charcot or Scottish douche.

50 West Forty-sixth Street.

\section{A FURTHER DISCUSSION ON MALARIA A WATERBORNE DISEASE.}

Read before the Mississippi Valley Medical Association at its twentieth annual meeting, at Hot Springs, Ark., Nov. 20, to 23, 1894.

\section{BY W. H. DALY, M.D.}

PITTSBURG, PA.

Ex-President of the Section of Laryngology of the Ninth International Medical Congress; Member of the American Climatological Associ. ation; Member of the American Laryngological Association; Senior Physician to the Western Pennsylvauia Hospital, Pittsburg, Pa.; Consulting Physician, Throat Department I'ittsburg Free Dispensary; Member of the British Medical Association.

A paper which I read before the American Climatological Association, in Washington, May 29, 1894, entitled, "Some Practical Observations on so-called Malaria being a Waterborne Disease," and published in the Medical Record of Sept. 15, 1894, has called forth in the Medical Record, and other medical journals, much correspondence pro and con; it has also brought to me many private letters from prominent. medical men, who have read my paper, many, in fact. most of them, not only indorsing my observations and views, but giving as a result of their own independent observations, data which strengthen the position I have been brought to contend for. I am pleased to learn of the widespread attention the paper has received, and only ask that the same unprejudiced observations will be resorted to that my paper comprehended, that every factor in the question shall be taken account of, and that causes and consequences shall be followed up, in considering both the evidence of the water,being the sole or chief vehicle of the Laveran corpuscle passing into the human organism, or the air we breathe, or whether both the air and water are the efficient vehicles of the germ finding its way into the blood, where we know it exists in the pathology of malaria; producing its manifestations, known to us as paludal fever, malarial fever, or chills and fever in its multiforms.

In summing up the evidence in a given case of socalled malaria, it is important to remember, that the water vehicles of malaria may include contaminated land water, taken in to the stomach on the stalks of celery, or on the leaves of lettuce, or it may find its vehicle in the rinsing of milk cans with malarial water, or in the adulteration of milk with contaminated water containing the Laveran germ; the cistern water stored under the earth may easily be contaminated by the earth water containing the germ, if the 
cistern itself is cracked or otherwise inefficient; the fact that the patient has drank at all of suspected water, even but once, ought to be taken into consid. eration, as the single.draught of contaminated water may have contained all the necessary germs for the infection of the blood and the production of the fever.

It can well be understood how the greatest care must be exercised in a malarial country to avoid taking into the stomach, some time or other, the germ in drinking water, and it will therefore appear at once, how necessary it is to exclude the water possibility, in making up data that will exclude the air theory of infection.

In order to define my position on this question, permit me to quote from my article in the New York Medical Record, of Sept. 15, 1894, wherein I say: "Twenty years' observations and studies on this subject, and investigations made in various districts from Manitoba to Louisiana, and all along the southern coast of the Atlantic Ocean, and of Cuba, Yucatan, and other districts in Mexico, lead the writer to the conclusion, that so-called malarial disease is not easily, if at all, contracted by inhaling so-called malaria or bad air, of the low, swampy, or new lands, but it is distinctly, if not almost exclusively, due to drinking the water that has come into contact with, and become infected with, the malarial germs or infusoria that exist in the earth and waters of the swamp and lowlands. This germ does not ordinarily, if at all, float in the air during the day, nor does it find easily a vehicle in the fog or vapors of the night. Indeed it is difficult to understand how one is to avoid the nightair, even if it is conceded to be deleterious-a conclusion I much doubt. Does any other air than night air exist at night? Is it possible to breathe any other? Is there any habitation sufficiently sealed against the outside air, to make the breathing of outside night air impossible?" It is the water alone that can and must be avoided; to avoid the air is quite impossible.

Touching the important general question of malaria, it is pertinent to quote from a recent review in the British Medical Journal of Oct. 27, 1894, of Dr. A. Laveran's work on "Paludism," as translated by Dr. J.W. Martin, of London, and printed by the New Sydenham Society for 1893 . The review says: "It is interesting to note the different ways in which two of the most important discoveries in pathology of modern times have been received. No sooner had Koch proclaimed the bacillus tuberculosis, than it was accepted with acclamation on all hands, immediately stamped as genuine, and passed as good current coin. This was in 1882. Two years before this date, in 1880, Laveran described the microörganism of malaria. The discovery was hardly recognized at the time, and even now, after a lapse of thirteen years, it excites so little interest that many are unaware that it has been made. The pathogenetic character of the schizomycetes (fungus or bacteria microbes) as a class had been well established long before Koch made his famous discovery, but no one suspected that an equally if not more important rôle is played by the protozoa (unicellular animals) as disease agents, until Laveran made his discovery. If we look at the matter from the practical point of view of sicknees and mortality, we find that bacillus tuberculosis is credited with one-seventh part of the total mortality of mankind; the malarial organism with one-half.
"For thirteen years the great discovery has been before the profession, and yet practically nothing, so far as Englishmen or Americans either, excepting Sternberg and a few others are concerned, has been done with it. We should like to know what practical teaching in the matter there is in our medical schools, particularly in our naval and military medical educational establishments. We wonder how many of the men whose principal future lifework will lie in combating this organism have been brought face to face with the thing itself, have actually seen their future enemy, or been taught how to search for it. In this matter our medical guides and teachers, both in this country and even in France itself, have a great deal to answer for. But signs of the recognition of the importance of Laveran's work are beginning to be discoverable. Evidence of this we have in the translation recently issued by the New Sydenham Society. We trust that this semi-official stamp of recognition will at last insure its general acceptance by our countrymen, or, at all events, its thorough investigation.

"Dr. Laveran's work is a very complete, temperate and judicial statement of all the more important modern views on the subject of the malaria parasite. In the course of the work the parasite in its polymorphic forms is carefully described; its bearing on the pathology of malarial disease and the practical outcome of our knowledge of the existence of such an organism are thoroughly discussed. Interesting chapters call attention to similar forms of parasitism among the lower animals, and detailed clinical evidence is given in abundance in support of many of the statements the author advances. Dr. Laveran expends a good many pages, we think unnecessarily, in defending himself from the repeated attempts which certain Italian investigators have made, to filch from him the credit of a certain and important part of his great discovery. Any one who has read his first large work and his numerous early papers knows very well with whom the entire merit of the discovery rests. Although stating them very fully, Laveran does not see his way to accept Golgi's views of the life cycle of the plasmodium, fascinating and original though they may be."

While the great question of malarial fever is one of widespread interest, it is the one phase of it that the writer is investigating, viz.: The waterborne means of infection. Laveran says:" "Numerous facts tend to prove that the infection may take place through drinking water, and that persons who have contracted paludism (malarial fever) have almost always made use of water of palustral (with humid or marshy soil) localities." He says further:

1. "It has been found repeatedly that in the same localities, among persons living under the same conditions, but drinking water from different sources, some were attacked by palustral fever while others escaped.

2. "In certain localities which were formerly insalubrious it has been sufficient to place pure water at the disposal of the inhabitants, instead of the stagnant water which was formerly used, for palustral fevers to disappear.

3. "In some localities, otherwise very healthy, people may contract fever, whose drinking water comes from unhealthy localities, and the persons most ex-

1 Paludism. By A. Laveran. New Sydenham Society, published 1893. 
posed to infection in these conditions are those who consumed most water.

4. "Travelers passing through unhealthy countries often succeeded in escaping fevers, by only drinking water that has been boiled, while people who do not take that precaution suffer severely."

Dr. Norbury ${ }^{2}$ in the Medical Record of Oct. 6, 1894, says on the subject of "Malaria a Waterborne Disease:" "I wish to add my experience and observation to the line of inquiry pursued by Dr. W. H. Daly, of Pittsburg, Pa., in his most excellent paper in the Medical Record of Sept. 15, 1894, regarding malarial infection. In the summer of 1881 , while employed under the directions of Maj. G. J. Lydecker, U. S. A., in the construction of the Kampsville Lock (Illinois River improvement), Kampsville, Calhoun County, Ill., I had the occasion to observe the effects of drinking water on persons temporarily residing in this malarial district, as well as upon the native inhabitants. The land immediately adjacent to the lock site was known as bottom land-it was overflowed at each high water season-and was poorly drained, being very flat. Water stood in the bogs or swamps until the dry weather of summer had completely evaporated it. Drinking water was obtained for the men employed in the construction of the lock foundations from drive wells, put down to the depth of twelve or fifteen feet. The men employed on the dredge and tow boats and the officers used filtered river water.

"Among the many laborers who sought employment were forty Swedes, who had arrived in this country from their native land about ten days before coming to the lock; they were a vigorous, well-nourished body of men, eager for work. They took board in quarters near the lock, and drank water from the drive well. Within ten days one of them was taken down with malaria, and before two weeks ten or more had succumbed; one died and two were seriously ill. At the end of a month but three were able to continue work; one of these had no malarial symptoms at all; he worked on one of the boats, where he drank filtered water. Now all of these men seemed peculiarly susceptible to malarial infection, and as quickly as they could returned to Chicago to escape its ravages. The men who worked on the boats escaped the disease. The natives who drank of the well water were not so much affected, yet quite a number of them had to quit work. The wells used by the natives, however, were located on the edge of the bluffs, about one-half mile from the river. Here we have, I think, marked evidence of the infection coming from drinking water; for all the employes, officers and all, were situated under like atmospheric conditions and exposed to the same heat, etc., during the day, yet those who used filtered river water escaped, while those using drive or open well water were afflicted. Some three and one-half years spent in engineering work on the Illinois River confirmed my belief in the possibilities of in. fection from water supply, rather than from atmos pheric conditions. I indorse Dr. Daly's views."

Since my paper appeared, Dr. Healy in a letter to the Record, asks some pertinent questions as to a solu. tion of an outbreak of malaria some four months ago in the Twenty-fourthWard, New York City, following the excavation for sewers, that can only be answered by a careful investigation on the ground, as to whether any of the persons taken ill : 1 , had drank from wells;
2 , had eaten lettuce, celery or other uncooked vegetables from paludal localities; 3 , whether any had drank milk from paludal localities where the cans may have been rinsed, or milk adulterated with palustral water (malarial).

Dr. Healy, however, says as to the drinking of contaminated water, being one of the prime factors: "I can offer proof positive in the person of myself. Some eight years ago the house in which I then resided, had for its water supply a cistern and a.well. After using this well water for drinking purposes for a few months I suffered from a severe attack of chills and fever. Upon investigation I found the well was receiving the leakage from an out house as well as the surface drainage. Upon discontinuing its use all symptoms disappeared."

Dr. R. D. Jewett, editor of the North Carolina Medical Journal, writes me in a private letter dated Oct. 22, 1894: "Your ideas are emphatically ours, and we believe that acceptance of this fact by our people will be a great boon to this section." And Dr. Jewett has in these few lines, the gist and great good of the whole question, viz., teach the people to drink only uncontaminated water, and you have made the great advance toward settling this question. And this is the chief end and aim of my several papers; for the accomplishment of that custom will go far toward settling the question of bow we are to prevent palustral fever, by eliminating what I believe to be quasi factors.

Dr. M. D. Hoge, Jr., of Richmond, Va., writes me in a private letter dated Sept. 19, 1894, as follows: "Your 'Observations on Malaria' in the last number of the Medical Record is one of the cleverest and most satisfactory articles on the subject I have ever read. I write to thank you for it, as a believer in your views for a long time past. To my mind it is the only rational and reconcilable theory on observations on this plague of our section. I am at present engaged in a study of the blood of cattle suffering from climatic fever, and hope to have something ready in a short while."

Dr. W. A. Plecker, of Hampton, Va., writes me in a private letter dated Sept. 18, 1894 :

"I am convinced that you are correct in your views, and am surprised that attention has not been more generally called to impure water as a source of malarial fever."

I have received many other letters of a similar tone, and there can be no doubt that it is the duty of the profession to cultivate a habit in their patients to drink only boiled or uncontaminated water in infected districts; since they can not avoid breathing the suspected air let us at least eliminate the water factor. I confidently predict we will then have successfully compassed the prevention of palustral (malarial) fever.

We all fully agree with Laveran's researches, and it is quite well known to all my hearers that damp, uncultivated, marshy or humid soils are those that offer the best medium for paludism. The existence, however, of marshes properly speaking is not necessary, and on the other hand all marshes do not cause fever, even in hot countries; at Tahiti in Australia and New Caledonia, both of which abound in marshes, palustral (malarial) fever is rare. If the marsh then is not necessary there must be a humid soil for the Laveran corpuscle to propagate itself. The small rains which take place at the end of the summer in 
hot countries, and which are soon dried up with the sun, are known to be very dangerous and productive of palustral (malarial) fevers. This fact has been observed by Dr. W. J. Lumsden, Dr. Oscar McMullen and others of Elizabeth City, N. C., who write me, saying: especially are these rains productive of new cases, as well as outbreaks of fever in old cases, among those who have drunk the water from surface wells, and the same facts are spoken of by Laveran and other observers.

The physical conditions here are evidently hot sun, brief fall of storm water, succeeded by hot sum, for the rapid growth and development of the paludal parasite; a long-continued rain, followed by colder weather are conditions unfavorable to development, as shown by the lesser multiplication of palustral disease.

There can be no doubt that the digestive juices are destructive to the palustral protozoa in the stomach, if the digestion is strong and healthful, but that condition, unfortunately, is not an ever present condition in those who drink water from palustral soil. Hence those who are most readily affected are such as are fatigued, weak, or under mental or physical strain or disease; anemia and privation also weaken the digestive vitality, and permit the passage of the parasite, through the diluted juices of the stomach into the blood. It has been so often demonstrated, as to be accepted as a fact, that parasites are devel. oped by preference in weakened constitutions, where vitality is already lowered, just as mosses and lichens invade the trunks of sickly trees and other vegetable growths.

"It seems," says Pasteur, "that vigorous life repels other life which wishes to graft itself upon it. It is when an individual grows weak that it becomes an easy prey to the parasites which besiege it, and it has been shown that by starving animals they can be made liable to disease, which they resist in their normal state.

"The period of incubation or latent stage of palustral (malarial) fever has been shown to be from seven to nine days, and the longest period seventeen years (latter problematical), and Mariotti and Ciarocchi, Cella and Marchiafava, Gualdi and Antolisei, and Angelini, made experiments which showed that, when palustral blood containing hematozoa is injected into the blood of man free from paludism (malaria), the fever appears in the inoculated subject on an average of ten days after the injection.

"The paludal hematozoa (malarial) in the blood live at the expense of the normal elements of it. The invaded red corpuscles grow paler and paler in proportion as the parasite develops, and it is probable that no anemia, except that resulting from hemorrhage, can be better explained than palustral anemia."

Professor Bouchard writes: "One thing seems certain to me, viz, it is that bacteria act in animals by the matters they secrete, and further, the fever of the infectious disease is toxic; it is provoked by diastases, such as that studied by Roux; by ptomaines, such as the amidaleine of Brieger."

A recent private letter from Dr. A. Laveran, of Paris, says:

"My Dear Confrere:-I thank you very sincerely for your article, which I have read with a great deal of interest. I think with you, that palustral infection has its place in water, and I am happy to see your new work which sustains
that view. One finds, moreover, in the water of palustral localities, organisms, very closely resembling the hematozoa of palustræ, but no onehas yet succeeded in proving the question, as to the form under which hematozoa is to be found in the medium outside of it.

Be pleased to accept, my dear confrere, this expression of my devoted sentiments."

I have made some unavoidable digressions in discussing the phase of this subject in which I am deeply interested, and have taken the liberty of quoting liberally from Laveran and others in the foregoing pages. It is within the easy province of every medical man to make researches on this question, unprejudiced by any theory, and as a practical means of testing the drinking water factor in paludal infection of the system. Let every physician and citizen in infected regions resolve to observe and advise the drinking of carefully stored storm water in cisterns above ground, and the boiling of land water, where such must by force of circumstances be used for potation. MIBJIOCRAPHY.

1. "Some Practical Observations on So-called Malaria being a Waterborne Disease." By W. T. Daly, M.I. Read before the American Climedical Record, Sept. 15, 1594 This essay called forth the following articles in discussion, pro and con

2. "Is Malaria a Waterborne Disease?" By Frank P. Norbury, M.D. Medical Record, Oet. 6, 1894 .

il "Some Practical Observations on Malaria Not Due to Drinking 13,1894 .

4. Editorial, "Malaria a Waterborne Disease." Indiana Medical Jonrnal, October, 1894.

5. "Is Malaria a Waterborne Disease?" By Isaac J. Jones, M.D.. Medical Record, Des 1, 1894.

6. "Is Malaria a Waterborne Disease?" By F. W. Dalrymple, M.D. edical Record, Nov. 10, 1894.

7. "Questions Concerning Malaria." By w. H. Daly, M.D., Medical Record, Dec. 1, 1894.

8. "Malaria and Drinking Water." By Rawlins Cadwallader. A.M., M.D., Medical Record, Dec. 15,1894 .

9. "Is Malaria a Waterborne Disease?" By E. Kershner, M.D., U.S.N., Medical Record, Jan, 5, 1895 .

10." Malaria a Waterborne Disease." By I. W. Zwisohn, M.D., Medical Record, Jan. 5, 1895 .

\section{ON THE VALUE OF KINESITHERAPY IN} GYNECOLOGIC PRACTICE.

Read before the Gynecological Society of Boston.

BY RICH HOGNER, M.D.

BOSTON, MAss.

The Swedish medical gymnastic was founded, developed and perfected, as is well known, in the beginning of this century by P. H. Ling, and to-day there is not a civilized country where its fame has not spread and where some medical gymnast has not located.

That the Swedish medical gymnastic is firmly grounded on scientific principles is best shown by the fact that regular physicians are beginning to take it up, as a specialty, more and more, and that the public has confidence in its ability in spite of the damaging influence of the so-called massagists, hardly half taught or self-made medical gymnasts, not to mention ignorant male and female administrators of baths, who do all that is possible to disgrace the name and drag down the method. But just as "wise old crones" and midwives have not been able to injure the scientific practice of gynecology and obstetrics, so have their counterparts in the field of medical gymnastics been unable to drag down the kinesitherapy. The labor of these impostors has created a wide gulf between the quack and regular medical gymnast, a gulf which will be widened still more in proportion as physicians study and themselves practice the manual treatment of diseases.

Swedish medical gymnastics reach the desired results by means of active and passive movements, increasing or decreasing the metabolism, regulating resorption in any given part of the body and by in- 